\title{
Replication as a Pedagogical Approach to Teaching Undergraduates
}

Qualitative Research Methods

\author{
By \\ Megan Becker \\ University of Southern California
}

\begin{abstract}
The importance of replication has been a major issue of discussion amongst political scientists for decades. However, in the last five years, the matter has gained greater traction, with many major journals adopting official standards for Data Access and Research Transparency (DA-RT). At the same time, scholars have suggested the pivotal role that replication might play in methods training for students. Unfortunately, these conversations have been somewhat limited, in that they place an emphasis on quantitative methods and training graduate students. This paper seeks to fill in this hole, offering commentary on the author's experience introducing a qualitative replication project in an upper-division undergraduate course. The students in the course replicated Michael Ross' (2004) influential paper on the resource curse, but the assignment framework can be adopted for a variety of topics and contexts.
\end{abstract}

Keywords: Pedagogy, Research Methods, Qualitative Research, Replication 


\section{Introduction}

In the Political Science classroom, faculty are charged with increasing students' substantive knowledge, while also encouraging them think deeply about 'how we know what we know.' Emphasizing research transparency in the classroom can serve both purposes - allowing students to learn more about the political world, while also getting a glimpse at the process of research. This article brings together two threads in recent discussions of political methodology: norms and practices around Data Access and Research Transparency (DA-RT)' and pedagogical approaches to research methods education, specifically qualitative methods education (Elman, Kapiszewski, and Kirilova 2015; Moravcsik 2014).

Much of the conversation surrounding research transparency in Political Science has been focused on professional researchers in academia (for some of the earliest examples, see King 1995 and Golden 1995). While this is important work, few scholars have considered how it might change our approach to teaching students about research. Greater transparency not only leads to better research overall, it also can de-mystify the process of research for those outside it. Letting students 'see under the hood' and understand the process of research in a lower-stakes setting may change their perspective on their course of study and inspire some to pursue independent research in the future.

This article describes my experience designing a course around a qualitative replication project, specifically having students replicate Michael Ross' (2004) influential paper on the resource curse and civil conflict. The course is a month-long intensive in research design and

\footnotetext{
${ }^{1}$ For an overview of DA-RT concepts and practices in Political Science, see Elman, Kapiszewski, and Lupia (2018). For specifically qualitative work, Elman and Kapiszewski (2018) offer an innovative approach to research transparency. Interested readers are also encouraged to review the outputs of the APSA's Qualitative Transparency Deliberations (2019), published online at: https://www.qualtd.net
} 
resource conflict for students at a large private research university. While the experience was shaped by the parameters of the course, this type of research project can be more broadly applied for different topics and a range of course contexts. The article concludes with suggestions for how faculty might adapt the exercise for their own courses.

\section{Qualitative Replication as a Pedagogical Practice}

Replication is a practice that has been identified by many as being a key modality for students learning research methods (e.g. Janz 2016). It functions though learning-by-doing and, because students are using materials that have been vetted in some way (usually via publication), they are less likely to chase down infeasible projects. The practice is also useful in that it allows students who may be nervous about the research process to do so with 'training wheels' (Druckman 2015).

While replication has largely been advocated when teaching quantitative methods (e.g. King 2006), that does not mean that it cannot or should not be done with qualitative work. In fact, several authors advocate for the development of projects in which undergraduate students are explicitly trained in qualitative methods (Elman, Kapiszewski, and Kirilova 2015) and/or that are expressly intended to replicate previous qualitative work (Moravscik 2014).

I took these suggestions seriously, devising a project that would allow undergraduate students to perform a qualitative replication in the context of a course on research design. Qualitative replication, while fairly rare, seemed ideal from a pedagogical perspective, as students entering in the class had varying levels of preparation in quantitative methods and I wanted to keep the focus on the evaluation of information, not learning a particular programming 
language or statistical technique (Bernstein and Allen 2013). Focusing on qualitative work allowed for greater emphasis on research design and causal mechanisms.

\section{Creating the Replication Assignment}

The assignment was meant to serve several purposes: 1) to improve students' understanding of research design and what goes into creating a piece of academic research; 2) to give them the experience of evaluating a research project, both substantively and in terms of the extent to which it engages in transparent research practices, 3) to allow them to work first-hand with qualitative case data in order to assess hypotheses of substantive importance.

For this exercise, I used several criteria to choose the study that the students would replicate. I specifically looked for an article:

1) on a topic of likely student interest;

2) that is part of an on-going, robust scholarly debate;

3) that was sufficiently explicit in terms of its case selection, operationalization of important concepts, and coding of cases;

4) that used a 'medium-N' approach, providing a variety of cases for students to explore.

Ultimately, I chose Michael Ross' "How do Natural Resources Influence Civil War?: Evidence from Thirteen cases," an article published by the journal International Organization in 2004. The work considers the relationship between natural resource wealth and civil war, an issue of great importance generally and one that, from experience, grabs students' attention. It is a foundational work in the scholarly debate around this issue and thoughtful critiques have been published about its methodology (Weller and Barnes 2016). Furthermore, with thirteen cases 
and thirteen hypotheses, there is plenty of material for students to work with in the replication exercise.

Once the article was chosen, it was necessary to determine an appropriate process for the project, described below, and delineate issues for students to address at each stage. This meant creating an assignment and assessment that captures students' mastery of the material and application, but is not dependent on a pre-determined outcome for the replication process.

\section{Introducing the Assignment to Students}

First, I needed to orient the students to the issue area under study and also help them gain an understanding of qualitative research methods and research transparency. There was varying level of preparation amongst the students: some had worked on faculty research projects before, while others were seeing the research process in action for the very first time. This required a carefully thought-out approach to support the gathering of evidence and the coding more generally.

The opening module of the course focused on teaching the students about research design, particularly focused on evaluating the different types of validity that might be claimed by an author of a study. It was also imperative to ensure that students felt comfortable reading and engaging with articles from academic journals. They were required to read chapters from Powner's (2014) book on how to read political science and how to engage with and in qualitative research. To facilitate their reading, I created an "empirical article checklist" (EAC) meant to guide them through a piece of research, making sure that they identified the important aspects of the study's research design and evidence. The EAC is included in the supplemental materials. 
We also spent time discussing the importance of transparency and replication, highlighting Lupia and Elman's (2014) categorizations of data access, production transparency, and analytic transparency. This framework is particularly useful for undergraduates because it is more practical and less abstract than some other work on research transparency and can be broken down into fairly straightforward questions: Does the author make their data accessible? Do they provide a full account of the procedures used to collect or generate the data? Do they clearly explain the links between their empirical data and their conclusions? Students were asked to answer these questions in order to evaluate Ross' paper in terms of research transparency and include their evaluation in their final paper.

In order to facilitate the students' work in a practical sense, they were given opportunities to meet with subject-librarians at our university. Students were advised on the resources available to them through the university library and had a separate session on strategies for research that they might use in their replication.

Students also need to be oriented to the substantive issues addressed in Ross' article. This involved having them read several articles on the relationship between natural resource wealth and civil war, particularly those that Ross was explicitly responding to (Collier and Hoeffler 2003, Fearon and Laitin 2003) and those that responded to Ross (Humphreys 2005, Weller and Barnes 2016).

\section{Facilitating the Replication Process}

Once the students felt more comfortable with the reading and got to know their way around the literature on resources and conflict, I introduced the replication assignment to them, making clear that the purpose of the assignment is engaging in the process of research. I took 
care to emphasize that this was not a 'gotcha' mission and that their grade was not tied to a particular outcome, but to their demonstration that they made a full-faith attempt to replicate the original study. The full assignment is included in the supplementary materials.

The first step of the actual replication process was to have each student read the Ross article individually and fill out the EAC to the best of their ability. Students were expected to come to class with their EAC completed and ready to discuss their assessment with the rest of the class. Some parts of the EAC are more straight-forward to answer than others and when there were differences across the students, they were encouraged to discuss their choices and come to a consensus. As the professor, I was prepared to act as final arbiter if a consensus could not be reached or if the students went off-path, but I did not have to intervene as much as I had anticipated. There certainly was spirited debate! Those wishing to apply this method in their own classrooms should feel free to intervene as they see fit, but a light hand is recommended, so that the students feel ownership in the project.

After the students had broken down the original article into its component parts, they sat down together to think about how to construct a codebook. Ross did not write a codebook for his article, but what are the clues to be found about how he made his coding decisions? When they went to original case material, how would they know which causal mechanisms were present and which were not? The students painstakingly reviewed all thirteen causal mechanisms covered by Ross and determined what counted as evidence of each mechanism. They tried to be as faithful to Ross as possible. As with the initial round with the EAC, the codebook was constructed based on consensus, with limited faculty input. I did weigh in when clarification or additional specificity in the coding rules was needed. 
With the codebook set, I assigned specific cases to the students. Each student was asked to replicate a certain number of the cases (for our project, two cases from the thirteen included in the original study). This way, multiple students were working on each case. Students were explicitly told not to work together on the case-work, and I introduced the concept of inter-coder reliability to explain the prohibition. Cases were assigned, taking into account student interest in a particular case or region. For the most part, students were given at least one of their firstchoice cases.

After the students had been working on their own cases for a week, ${ }^{2}$ we arranged for them to meet with Ross. ${ }^{3}$ While this will not be possible in all cases, faculty interested in designing a similar exercise should consider approaching the author of the study to see if they would be willing to talk to students. Our group found the interaction to be incredibly valuable and several mentioned it in their evaluations that it was their favorite part of the course. Before the meeting, we asked them each to devise a series of questions for Ross, which we then vetted. We were very fortunate in that Ross was willing to answer all of the students' questions with great candor, which gave them greater insight into the process of research. He also shared his case notes, which provided an additional source of material for the replication. The students' experiences were greatly enriched by Ross' cooperation.

To facilitate the students' work on their final projects, I held regular progress meetings, both one-on-one and with the entire class. This was helpful, not just for the purposes of completing the replication, but also for thinking through implications of various research design choices and devising creative solutions for finding more data to include in future analysis. As

\footnotetext{
${ }^{2}$ Note that this was a month-long intensive course, in which students were expected to dedicate their time entirely to this class; those wanting to adapt the assignment may need to adjust the timeline.

${ }^{3}$ Meeting or working with the original author is also suggested by Janz and Freese (2019) as a best practice for replication.
} 
students gained confidence in their grasp of the material and the research design issues at hand, they generated ideas for how we might extend Ross' analysis to an additional set of cases and included those ideas in their final project reports.

Keeping in mind the course emphasis on research transparency, one of the major points that I stressed was documentation. Documentation is critically important for research transparency and I encouraged the students be as transparent as possible in their replication. They were required to create a "Data Appendix" for their work, a compendium of the sources that they used, particularly highlighting the information that informed their coding choices. Data appendices are digital and include excerpts from articles and scans of books with important information highlighted, providing Lupia and Elman's (2014) data and production transparency. Students were also asked to submit a set of 'coding notes' that explained their choices in evaluating each of the thirteen hypotheses, providing analytic transparency. We discussed how to organize and present the Data Appendix so that it would be useful for others and students reviewed sample appendices.

As they completed the replication, students were asked to prepare a one-to-two-page reflection on the experience as part of their final project submission to encourage metacognitive skills and to preserve the stated focus on process over outcome (Hosein and Rao 2017). Again, students were not assessed on whether they achieved a particular outcome, but rather how they went about the replication and how well their final product achieved the goals of data access, production transparency, and analytic transparency (Lupia and Elman 2018). 


\section{Application in Other Contexts}

Faculty who are interested in using this method of teaching students about research should feel free to apply the process to research in their areas of their own expertise. The assignment is agnostic in terms of the topic of the paper, but for practical purposes, I recommend that your chosen study have at least some of the following attributes. First, qualitative work that is 'medium- $\mathrm{N}$ ' is more likely to engage students because they can work on different cases and compare and contrast their experiences coding different countries, time periods, etc. However, it is ultimately up to the faculty to decide how many cases are appropriate for the size of their class. Second, the work should be on a matter under debate currently with 'real-world' implications. While few academic debates are definitively 'settled,' students are energized by the idea of contributing to our knowledge of a topic, particularly if it has direct policy implications. Faculty would do well to seek out topics within their academic expertise that are more likely to engage students. ${ }^{4}$

Third, faculty should make sure that any potential replication does not require access to specialized sources that are unavailable to students. For this reason, studies covering more contemporary cases may be preferable, as students may not have access to archival materials. Furthermore, faculty are advised to verify that the documents necessary to complete the study are available in English or an easily accessible translated form. This is an area where university librarians can be excellent resources for faculty, as they may be able to point you to resources, archives or other special collections on campus that students may utilize for their projects.

\footnotetext{
${ }^{4}$ I wish to note that, while some faculty might find it easiest to replicate research of their own, this is unlikely to be the best choice pedagogically. Students might feel pressure to completely reproduce their professor's findings and it might stymie the questions and lively discussions that one hopes to engender.
} 
Not every piece of research considered for replication will have all of these characteristics. In my areas of research, Page Fortna's (2004) book Peace Time about variation in cease-fire agreements in civil wars and how they might lead to a more or less durable peace or Haggard and Kaufman's (2012) article on democratic transitions might be fruitful source material for qualitative replication projects. In the end, it is incumbent upon the faculty member to choose the piece they feel is most appropriate for their students.

Furthermore, not all classes are the same in their size, time-span, or level of preparation amongst students. Again, this was a fairly small one-month intensive upper-division course, meaning that I was afforded lots of time to work with the students and ensure that they were well-prepared for the task.

Nevertheless, the project will be applicable in a variety of course contexts. For example, one might want to apply the assignment in a larger class, something I am currently in the process of preparing. The assignment is flexible to allow for students to work in teams and it should not jeopardize their educational experience. ${ }^{s}$

One might also want to apply this project in a lower-division class or adjust for students with varying levels of preparation. One advantage of the assignment is that it can be used in a modular way, dividing up tasks as appropriate. Faculty may want to ask students to use the empirical article checklist as they read or apply the concepts laid out by Elman, Kapiszewski, and Lupia (2018) to evaluate the level of research transparency of a particular article; one might ask students to read a codebook and assess a particular set of coding decisions made by an author or create a Data Appendix for a paper.

\footnotetext{
${ }^{5}$ For more on using team-based research projects in Political Science courses and an excellent discussion of their advantages and disadvantages, see Knoll (2016).
} 
Additionally, this method of teaching students about the practice of qualitative research through replication may also be useful for graduate study (Moravcsik 2014). Graduate students are unlikely to have had training in qualitative methods during their undergraduate career, as Political Science programs' major requirements have great variation in terms of whether they require a research methods course and the type of methods that are taught in such courses (Thies and Hogan 2005; Turner and Thies 2009; Parker 2010). Having early-career PhD students engage in replication can be excellent practice for developing the skills they may need for their own future research projects.

Whatever the context or specific topic of study, qualitative replication is a pedagogical practice that can open up the process of research to students and empower and inspire them to see themselves as researchers, contributing to our collective knowledge of the political world. 


\section{Works Cited}

Bernstein, Jeffrey L., and Brooke Thomas Allen. "Overcoming methods anxiety: Qualitative first, quantitative next, frequent feedback along the way." Journal of Political Science Education 9.1 (2013): 1-15.

Druckman, James N. "Research and Undergraduate Teaching: A False Divide?:

Introduction." PS: Political Science \& Politics48.1 (2015): 35-38.

Elman, Colin, and Diana Kapiszewski. "Data access and research transparency in the qualitative tradition." PS: Political Science \& Politics 47.1 (2014): 43-47.

Elman, Colin, and Diana Kapiszewski. "The Qualitative Data Repository’s Annotation for Transparent Inquiry (ATI) Initiative." PS: Political Science \& Politics 51.1 (2018): 3-6.

Elman, Colin, Diana Kapiszewski, and Dessislava Kirilova. "Learning through research: Using data to train undergraduates in qualitative methods." PS: Political Science \& Politics 48.1 (2015): 39-43.

Elman, Colin, Diana Kapiszewski, and Arthur Lupia. "Transparent Social Inquiry: Implications for Political Science." Annual Review of Political Science (2018).

Fortna, Virginia Page. Peace time: Cease-fire agreements and the durability of peace. Princeton University Press, 2004.

Golden, Miriam A. "Replication and non-quantitative research." PS: Political Science \& Politics 28.3 (1995): 481-483.

Haggard, Stephan, and Robert R. Kaufman. "Inequality and regime change: Democratic transitions and the stability of democratic rule." American Political Science Review 106.3 (2012): 495-516.

Hosein, Anesa, and Namrata Rao. "Students' reflective essays as insights into student centredpedagogies within the undergraduate research methods curriculum." Teaching in Higher Education 22.1 (2017): 109-125.

Humphreys, Macartan. "Natural resources, conflict, and conflict resolution: Uncovering the mechanisms." Journal of conflict resolution 49.4 (2005): 508-537.

Humphreys, Macartan, and Alan M. Jacobs. "Mixing methods: A Bayesian approach." American Political Science Review 109.4 (2015): 653-673.

Janz, Nicole. "Bringing the gold standard into the classroom: replication in university teaching." International Studies Perspectives 17.4 (2016): 392-407. 
Janz, Nicole and Jeremy Freese. "Good and Bad Replications in Political Science: How Replicators and Original Authors (Should) Talk to Each Other" Working Paper. Available at: https://www.mzes.uni-mannheim.de/openscience/wp-content/uploads/2019/01/Janz-Freese_Good-and-Bad-Replications-1.pdf

King, Gary. "Replication, replication." PS: Political Science \& Politics 28.3 (1995): 444-452.

King, Gary. "Publication, publication." PS: Political Science \& Politics 39.1 (2006): 119-125.

Knoll, Benjamin R. "Learning by doing: Mentoring group-based undergraduate research projects in an upper-level political science course." PS: Political Science \& Politics 49.1 (2016): 128131.

Lupia, Arthur, and Colin Elman. "Openness in Political Science: Data Access and Research Transparency." PS, Political Science \& Politics 47.1(2014): 19-42.

Moravcsik, Andrew. "Transparency: The Revolution in Qualitative Research." PS, Political Science \& Politics 47.1 (2014): 48-53.

Parker, Jonathan. "Undergraduate research-methods training in political science: A comparative perspective." PS: Political Science \& Politics 43.1 (2010): 121-125.

Powner, Leanne C. Empirical research and writing: A political science student's practical guide. CQ Press, 2014.

Ross, Michael L. "How do natural resources influence civil war? Evidence from thirteen cases." International Organization 58.1 (2004): 35-67.

Thies, Cameron G., and Robert E. Hogan. "The state of undergraduate research methods training in political science." PS: Political Science \& Politics 38.2 (2005): 293-297

Turner, Charles C., and Cameron G. Thies. "What we mean by scope and methods: A survey of undergraduate scope and methods courses." PS: Political Science \& Politics 42.2 (2009): 367373.

Weller, Nicholas, and Jeb Barnes. "Pathway analysis and the search for causal mechanisms." Sociological Methods \& Research 45.3 (2016): 424-457. 


\section{Purpose of the Assignment}

During this course, you have learned about the principles of research design in social science, using examples from scholarly work on the intersections between ecology and security. For your final paper, you will demonstrate your mastery of the material by replicating a seminal work in the political science literature on the "resource curse," cited here:

Ross, Michael L. "How do natural resources influence civil war? Evidence from thirteen cases." International Organization 58.1 (2004): 35-67.

Replication is important in any scientific field, as if we want to be sure of our scientific discoveries, they must pass multiple tests. This would preferably involve using different research designs and multiple tests of the same research design. The more consistency across these different tests, the more confidence we have that our theories are correct in their predictions about the empirical world. For more on matters of research transparency in Political Science, please see the course reading by Lupia and Elman (2014).

In order to replicate a study, we must both reproduce the empirical data used to test the hypotheses and replicate the analysis of that data. You will be asked to go beyond a simple replication of the previous study and 1) analyze the strength and limitations of the previous study, 2) identify the implications of those strengths and limitations for the validity of the study's findings, and 3) suggest improvements that could be undertaken in future research.

Process The following steps give a rough guideline to the project. You will meet with me regularly during the term to discuss your progress.

1) Read the article and record your answers to the Empirical Article Checklist provided in class. We will spend time in-class reviewing the article and discussing your answers to the prompts. Please prepare for an in-depth discussion. The better your understanding of the original article, the better your final product (and the less painful the process).

2) Assignment of replication cases. Each student will be asked to replicate two cases from the 13 included in the study. Cases will be assigned by the professor, taking into account student interest and/or expertise.

3) Gather evidence on your assigned cases. Your first job is to scour the original paper for all resources used in your case. You will also be expected to do outside research in order to fully evaluate the original analysis. You are encouraged to consult with the professor and subject librarians on campus to help you in your search for materials.

4) Replicate Ross' analysis. Look at the sources Ross used and reach your own conclusions about the validity of the research findings.

5) Write up your findings in your final paper. See next section for details. 


\section{Final Paper}

Your replication paper should have the following parts (labeled as such in the text) and answer the questions delineated for each part.

\section{1) Abstract}

Summarize your entire paper in 3-5 sentences (save this for last).

\section{2) Introduction}

What is the author's research question?

What theories being tested that purport to answer this question?

What are the author's key findings?

How does this paper fit into the literature on the resource curse generally and the relationship between natural resources and civil conflict specifically?

\section{3) Theory}

What is/are the independent variable(s)?

What is/are the dependent variable(s)?

What is/are the causal mechanism(s) or intermediate variable(s)?

What theoretical predictions are being assessed?

\section{4) Research Design}

What cases and evidence does the author select?

What is the author's justification for this research design?

What are the advantages to this research design?

What are the limitations of this research design?

How does the author define and operationalize the key independent, intermediate and dependent variables? 


\section{5) Evaluation of Data Access and Research Transparency (Please see Lupia and Elman 2014 for explication of these concepts)}

Data Access: Does the author reference the data used to support their empirical claims? Describe the data and where it came from. If the data is the author's own, do they provide access to this data or explain why they cannot?

Production Transparency: Explain the procedures and note any missing information.

Analytic Transparency: Does the author clearly explain the links between their empirical data and their conclusions? Please describe.

\section{6) Empirical Replication}

What are the author's key findings?

Keeping in mind the principles of research transparency, describe the data and your efforts to replicate the original study.

Does your replication of the author's analysis clearly support the original findings?

If not, which of the findings are not clearly supported? Why does the evidence not clearly support the author's findings?

\section{7) Analysis and Implications}

Is the evidence consistent with an alternative theoretical prediction or interpretations?

What alternative research design might you employ to assess the authors' theoretical predictions?

What additional evidence and cases might you select?

What are the implications of your findings for the scholarship on this question and for policy more generally? 


\section{8) Data Appendix}

Putting together an informative appendix is an unappreciated art, particularly, as researchers are limited in the number of words they may use to address a problem in a journal article. Please include the following materials:

\section{Empirical Article Checklist}

All data collected: this may include articles, newspaper entries, passages from books, scans of archival materials, quantitative data, etc. Please consult the professor if you have questions about what to include.

\section{9) Reflection}

A one- to two-page reflection on the process of producing your paper. What surprised you the most or the least about the process? What did you learn? What would you change? 